\title{
HÁ DILEMAS MORAIS? ${ }^{1}$
}

\section{ARE THERE MORAL DILEMMAS?}

\author{
PEDRO MERLUSSI ${ }^{2}$ \\ (DURHAM/ Inglaterra)
}

\begin{abstract}
This essay discusses the question whether there are moral dilemmas. The conclusion is that they do not exist. It has three main parts. In the first one, it tries to refute one version of the phenomenological argument. In the second part, the essay puts forward three arguments against the existence of moral dilemmas. Plus, it uses Fara's analysis (2008) of masked abilities in order to reply to some counterexamples to the principle that 'ought implies can'. The last part of this essay is an attempt to explain why the intuition that moral dilemmas exist is illusory.

Keywords: moral dilemmas; the phenomenological argument; ought implies can; masked abilities.
\end{abstract}

\section{RESUMO}

Este ensaio discute o problema de saber se há dilemas morais. A conclusão é a de que eles não existem. Ele tem três partes principais. Na primeira delas, ele tenta refutar uma versão do argumento fenomenológico. Na segunda parte, o ensaio apresenta três argumentos contra a existência de dilemas morais. Além disso, ele usa a análise de Fara (2008) de capacidades mascaradas para responder a alguns contraexemplos ao princípio de que "dever implica poder". A última parte deste ensaio é uma tentativa de explicar por que a intuição de que dilemas morais existem é ilusória.

Palavras-chave: dilemas morais; o argumento fenomenológico; dever implica poder; capacidades mascaradas.

\section{Introdução}

Um oficial nazista aparece à porta de sua casa perguntando pelo paradeiro de um amigo judeu que está escondido dentro dela. Você sabe que seu amigo será morto se você revelar o local preciso em que ele se esconde. Suponhamos que você tenha a obrigação, em quaisquer circunstâncias, de dizer a verdade. Por isso, tem a obrigação de dizer onde seu amigo se encontra. Mas suponha também que tem a obrigação de salvar a vida de seu amigo. Se disser a verdade, seu amigo será morto e você não cumprirá o dever de salvar a vida dele. Se, por outro lado, escolher salvar a vida de seu amigo enganando o oficial nazista, deixa de dizer a verdade e, por isso, não cumpre uma obrigação. Este é um possível caso de dilema moral. Trata-se de uma situação na qual um agente está obrigado a realizar pelo menos duas ações e, no entanto, está impossibilitado de realizá-las conjuntamente. 
O problema que discuto neste ensaio é o de saber se há dilemas morais. Defendo que é plausível pensar que não. Há, no entanto, diversos argumentos contra essa tese. Na primeira parte deste ensaio, formulo e discuto um dos argumentos mais influentes: o argumento fenomenológico. Depois disso, mostrarei que, caso aceitemos alguns princípios plausíveis, teremos de recusar a existência de dilemas morais. Mas essa conclusão é prima facie implausível: intuitivamente parece haver dilemas morais genuínos. A última etapa deste ensaio é uma tentativa de explicar por que esta intuição é uma ilusão. Argumentarei que nossas intuições atestam que se trata de um caso no qual não sabemos o que fazer (em virtude de nossa limitação cognitiva), mas não que seja um conflito genuíno de obrigações.

\section{Dilemas morais}

O exemplo que usei na introdução não é o único caso de um suposto dilema moral. Joshua Green, por exemplo, apresentou um exemplo famoso (cf. Greene, 2009), que foi inicialmente apresentado por Foot e Thomson. Suponha que um trem desgovernado irá atingir cinco pessoas que trabalham desprevenidas sobre uma linha férrea. Você tem a chance de salvá-las ao acionar a alavanca do trem. Mas, se fizer isso, o trem atingirá uma pessoa que está presa sobre os trilhos. Novamente, parece que você tem o dever de salvar essas seis pessoas, embora seja incapaz de o fazer.

Este exemplo mostra que é plausível pensar que há dilemas morais. Para já, será preciso caracterizar o termo "dilema moral” com mais precisão. Aceitando que "O $A$ " abrevia "é obrigatório que A", e "C $A$ " abrevia "é capaz de $A$ ", é comum oferecer a seguinte caracterização de "dilema moral” (McConnell, 2010: §4):

D.M: $(\mathrm{O} A \wedge \mathrm{O} B) \wedge \neg \mathrm{C}(A \wedge B)$

Defendo que é plausível pensar que não há qualquer circunstância que torne aquela proposição verdadeira. Mas a defesa dessa tese enfrenta dois problemas inicias. Primeiramente, é intuitivo pensar que dilemas morais são efetivos. Os casos do assassino curioso e do trem desgovernado parecem apontar justamente nessa direção. Em segundo lugar, há argumentos que procuram nos persuadir a aceitar justamente a conclusão de que é plausível pensar que há dilemas morais. Na seção seguinte discutirei um desses argumentos. Na última seção procuro mostrar que a 
nossa intuição não é um indício forte o bastante para aceitar um conflito genuíno de obrigações.

Antes de prosseguir, entretanto, é importante notar uma distinção entre os conflitos epistêmicos e ontológicos de obrigações. Os conflitos epistêmicos envolvem duas ou mais supostas obrigações em que o agente não sabe o que fazer. Os conflitos ontológicos são mais fortes: a proposição de que um agente não sabe o que fazer entre dois supostos cursos de ação obrigatórios não é condição suficiente para haver um conflito genuíno de obrigações. Isso porque a existência de um conflito genuíno de obrigações é independente da crença do agente acerca dele. Por essa razão, é adequado referir tal conflito com o termo "ontológico". Dilemas morais genuínos, suponho, são conflitos desse último tipo. A seção seguinte considera um argumento a favor do conflito ontológico de obrigações.

\section{Um argumento fenomenológico}

O argumento que apresentarei é o que se tem denominado por vezes de “argumento fenomenológico", pois recorre às emoções que um agente experiencia diante de um suposto conflito de obrigações. Os defensores mais proeminentes desse tipo de argumento são Williams (1965) e Marcus (1980). A apresentação que farei se baseia em alguma medida nas discussões de Williams sobre o conceito de arrependimento, embora ele mesmo reconheça que seja pouco claro sobre isso (Williams, 1965: p.103).

Considere um suposto caso de dilema moral, descrito no livro A Escolha de Sofia. Dois filhos - um menino e uma menina - de uma prisioneira polonesa serão executados por nazistas num campo de concentração. Mas os nazistas permitem que essa prisioneira, a Sofia, escolha salvar a vida de um dos filhos; e eis que ela acaba decidindo salvar a vida do garoto. Neste caso, o agente se encontra diante de uma situação de arrependimento. Nessa situação, o sentimento de arrependimento é apropriado, não importando o curso de ação que Sofia escolha realizar. E esse arrependimento é apropriado, argumentam os proponentes do argumento fenomenológico, apenas quando o agente não cumpre com o dever; portanto, mesmo que Sofia não seja capaz de realizar os dois cursos de ação, salvar a vida do garoto e salvar a vida da menina, ela tinha a obrigação de salvar a vida da menina e tinha a 
obrigação de salvar a vida do garoto, já que se arrependeu apropriadamente. Portanto, a situação na qual Sofia se encontra é um caso genuíno de dilema moral.

Embora essa seja uma maneira comum de apresentar esse argumento (cf., por exemplo, McConnel, 2010, §6), ela é muito imprecisa. Eis uma maneira mais precisa de formular o argumento:

1. Se $S$ está diante de um dilema moral, então se arrepende apropriadamente.

2. $S$ se arrepende apropriadamente

3. Logo, $S$ está diante de um dilema moral.

No caso acima apresentado, Sofia - diante da circunstância em que se encontra - pode realizar apenas duas ações: salvar a vida do filho ou salvar a vida da filha (note que a disjunção ali é exclusiva). Se Sofia escolhe salvar a vida do garoto, irá se arrepender por não ter salvado a vida da filha. Por outro lado, se Sofia salvar a vida da filha, arrepender-se-á de não ter salvado a vida do garoto. Esse caso ilustra a plausibilidade da primeira premissa. Se um agente realmente está diante de um dilema natural, parece natural esperar que ele se arrependa. Como Sofia se arrepende apropriadamente por salvar a vida do garoto, segue-se que ela estava diante de um dilema moral.

A primeira e óbvia objeção ao argumento, tal como formulado, é a de que é dedutivamente inválido, já que inferir 3 a partir de 1 e 2 é incorrer na falácia da afirmação da consequente. Mas essa objeção não é persuasiva. $\mathrm{O}$ argumento não é dedutivo, pois é uma inferência a favor da melhor explicação, que chamarei de agora em diante de IME. E do fato de um argumento não ser dedutivo não se segue que seja falacioso. Bons argumentos indutivos obviamente não são dedutivos. Um defensor desse argumento dirá que a melhor explicação para $S$ estar arrependido é ele estar diante de um dilema moral. Como se trata de uma IME, se as premissas são verdadeiras, então a conclusão é provavelmente verdadeira. Portanto, quando um agente está numa situação como a da escolha de Sofia, e se arrepende apropriadamente, é provavelmente verdade que o agente estava diante de um dilema moral.

Um aspecto importante da IME é saber o que a distingue da falácia da afirmação da consequente. Não pode ser a forma lógica, pois tanto a falácia da afirmação da consequente quanto a IME tem a seguinte forma argumentativa: 
1. Se $\mathrm{P}$, então $\mathrm{Q}$

2. $\mathrm{Q}$

3. Logo, $\mathrm{P}$

Para resolver esse problema, pressuporei que a expressão "se P, então Q" da primeira premissa refere-se a uma relação causal, no caso da IME, e não à implicação material, como no caso da falácia da negação da antecedente. Assim, no argumento fenomenológico apresentado, o arrependimento apropriado de $S$ é o efeito da ação de $S$ estar diante de um dilema moral.

O argumento é cogente? Há razões para pensar que não, creio. E a razão principal é que não há uma relação causal entre os eventos descritos por $\mathrm{P}$ e por $\mathrm{Q}$. A relação causal que há, penso, é entre o arrependimento apropriado de $S$ e a sua crença de que está diante de um dilema moral:

1. Se $S$ acredita que está diante de um dilema moral, então arrepende-se apropriadamente.

A melhor explicação para o sentimento de arrependimento apropriado de $S$ é a sua crença de que está diante de um dilema moral, não o próprio dilema. Mesmo que Sofia não estivesse perante um dilema moral, e acreditasse que um de seus filhos morreria, independentemente da ação que realizaria, é plausível pensar que ela sentiria arrependimento. E mesmo que Sofia estivesse diante de um dilema moral, mas não acreditasse nisso, é plausível pensar que ela não sentiria arrependimento. $O$ que é relevante para o sentimento de arrependimento é a atitude doxástica do agente. E, como se sabe, o verbo "crer" não é factivo. Do fato de $S$ acreditar que está diante de um dilema moral não se segue que esteja de fato diante de um dilema moral. Se ao salvar a vida da filha, ela não acreditasse que o seu filho iria morrer, Sofia não iria se arrepender da ação que realizou. $\mathrm{O}$ argumento falha por não considerar uma hipótese alternativa mais plausível: a melhor explicação do arrependimento de um agente não é o dilema moral, mas a crença do agente de que está diante de um dilema moral.

Você poderia dizer que minha formulação do argumento é pouco caridosa e que eu deveria ter incluído a crença do agente de que ele estava diante de um dilema moral. Eu na verdade estava presumindo que o agente acreditava estar diante de um 
dilema moral quando formulei o argumento original. Isso não resolve o problema, no entanto. Quer dizer, não resolve o problema para o defensor do argumento do ontológico. Mesmo que o agente acredite estar diante de um dilema moral e de fato esteja, o que o argumento permite concluir é que ele acreditava estar diante daquele dilema, nada mais. O que será a melhor explicação para o seu arrependimento apropriado continuará a ser sua crença, não obstante ele esteja diante de um dilema genuíno.

Outra réplica poderia ser a seguinte: o argumento é imune à minha objeção se levarmos em conta a cláusula "apropriado" na sua formulação. No primeiro caso, quando Sofia experiencia o arrependimento, mesmo apesar de não estar diante de um dilema moral, tal arrependimento não é apropriado. E o que conta é precisamente experienciar um arrependimento apropriado. O dilema moral é causa do arrependimento apropriado, mas não de um simples arrependimento. Entretanto, esse tipo de resposta não é convincente, pois o argumento se torna uma petição de princípio. "Arrependimento apropriado", nesse contexto, significa "aquilo que um agente sente diante de um dilema moral”. Assim, a premissa de que $S$ se arrepende apropriadamente já pressupõe que $S$ está diante de um dilema moral. Ora, assumir que $S$ está diante de um dilema moral é a conclusão que o defensor do argumento fenomenológico tem de nos persuadir a aceitar, e não meramente pressupor. Nessa formulação, o argumento é uma petição de princípio.

Se a objeção que apresentei está correta, o argumento fenomenológico não nos compele a aceitar a provável existência de dilemas morais. Mesmo que o argumento não seja cogente, parece haver casos intuitivos de dilemas morais genuínos e é, portanto, plausível pensar que há dilemas morais.

Uma solução à primeira vista plausível consiste em traçar uma distinção entre o dever prima facie e o dever simpliciter (cf. Ross, 1930: cap. 2). Suponho que o leitor tenha achado o exemplo do assassino curioso um mau exemplo. E de fato estou disposto a aceitar isso. Eis uma resposta razoável com base na distinção entre os deveres simpliciter e prima facie. Num suposto dilema, tal como no assassino curioso, o dever de não mentir, por exemplo, é prima facie. Um dever $A$ é prima facie se, e só se, é um dever realizá-lo a menos que exista outro dever prima facie $B$ que revoga o dever prima facie de $A$. No caso do assassino curioso ocorre justamente isso. O dever prima facie de salvar a vida do amigo revoga o dever prima facie de não mentir. 
Portanto, se pressupusermos que os deveres são prima facie, soluciona-se esses supostos dilemas morais.

No entanto, esse tipo de resposta não parece convincente. Não é claro como o dever prima facie soluciona casos de deveres simétricas. Considere um exemplo reformulado da escolha de Sofia. Suponha que, ao invés de ter um garoto e uma menina, Sofia seja mãe de dois bebês gêmeos. Ela tem o dever de salvar o bebê $A$ e tem o dever de salvar o bebê $B$, mas não há dever prima facie nesse suposto dilema moral. O dever de salvar o bebê $B$ não revoga o dever de salvar o bebê $A$ (e viceversa). O problema ainda permanece.

Há uma maneira de responder essa objeção, mas irei explorá-la apenas no final deste ensaio. A seção seguinte procura mostrar que a suposição da existência de dilemas morais somada a algumas suposições plausíveis, leva-nos a uma contradição. E por isso seria razoável negar a suposição que nos levou à contradição, a saber, a suposição de que há dilemas morais.

\section{Consistência e dilemas morais}

Procurarei mostrar que é inconsistente aceitar a existência de dilemas morais com alguns princípios plausíveis. Na bibliografia sobre o problema, há dois argumentos principais. O primeiro recorre aos dois seguintes esquemas:

Princípio da Consistência Deôntica (PC): uma mesma ação não pode ser conjuntamente obrigatória e proibida.

Princípio da Lógica Deôntica (PD):se, necessariamente (no sentido de ser fisicamente necessário), $A$ acarreta $B$, então a obrigatoriedade de $A$ acarreta a obrigatoriedade de $B$.

Formalizados, os dois esquemas são estes:

(PC): $O A \rightarrow \neg \mathrm{O} \neg A$

(PD): $\square(A \rightarrow B) \rightarrow(\mathrm{O} A \rightarrow \mathrm{O} B)$ 
O dilema moral foi caracterizado anteriormente da seguinte maneira:

(DM): $(\mathrm{O} A \wedge \mathrm{O} B) \wedge \neg \mathrm{C}(A \wedge B)$

$\mathrm{O}$ argumento pode ser apresentado como se segue:

1. $(\mathrm{O} A \wedge \mathrm{O} B) \wedge \neg \mathrm{C}(A \wedge B)$

2. $\mathrm{O} A \wedge \mathrm{O} B$

3. $\neg \mathrm{C}(A \wedge B)$

4. $\square \neg(A \wedge B)$

5. $\square(\neg A \wedge \neg B)$

6. $\square(A \rightarrow \neg B)$

7. $\square(\mathrm{A} \rightarrow \neg \mathrm{B}) \rightarrow(\mathrm{OA} \rightarrow \mathrm{O} \neg B)$

8. $\mathrm{OA} \rightarrow \mathrm{O} \neg B$

9. $\mathrm{O} A$

10. $\mathrm{O} \neg B$

11. $\mathrm{O} B$

12. $\mathrm{O} B \rightarrow \neg \mathrm{O} \neg \mathrm{B}$

13. $\neg \mathrm{O} \neg \mathrm{B}$

14. $\mathrm{O} \neg \mathrm{B} \wedge \neg \mathrm{O} \neg \mathrm{B}$ suposição (dilema moral).

de 1

de 1

de 3

de 4

de 5

instância de PD

de 6 e 7

de 2

de 8 e 9

de 2

instância de PC

de 11 e 12

de 11 e 14

Como 14 é uma contradição, temos de negar a suposição que permitiu derivála:

15. $\neg((\mathrm{O} A \wedge \mathrm{O} B) \wedge \neg \mathrm{C}(A \wedge B)) \quad 1-14 \mathrm{I} \neg$

15 é a conclusão de que não há dilemas morais. Um dos passos disputáveis desse argumento, e que é independente de PD e PC, é precisamente o 4: inferir $\square \neg$ $(A \wedge B)$ a partir de $\neg \mathrm{C}(A \wedge B)$. Esta inferência merece uma discussão muito mais pormenorizada, a qual será negligenciada neste artigo. A única coisa que posso dizer é que não é simples mostrar que a inferência é inválida. Apresentarei um argumento independente dessa inferência ao leitor que não estiver convencido de sua validade. 
PC é certamente o princípio menos controverso. Intuitivamente, o que esse princípio diz é que uma ação não pode ser simultaneamente obrigatória e proibida. PD também é muito básico, e mesmo os proponentes da existência de dilemas morais o aceitam. É o caso, por exemplo, de E. J. Lemmon (1965: p.40) e van Fraassen (1973: p.15). Pode-se argumentar que PD é falso porque há dilemas morais genuínos. Mas esse argumento, no entanto, é uma petição de princípio. O que precisamos ver é se há razões independentes para pensar que PD é falso. O problema é o de saber se há dilemas morais genuínos, e não estou propenso a aceitar que PD é falso porque há dilemas morais.

O segundo argumento recorre também a dois princípios. São estes:

Princípio de Aglomeração (PA): Se é obrigatório fazer A e obrigatório fazer $B$, então é obrigatório fazer $A$ e $B$.

Princípio de que dever implica poder (PDP): Se uma ação é obrigatória, então um agente é capaz de realizá-la.

Formalizados, os dois princípios são estes:

(PA): $(\mathrm{O} A \wedge \mathrm{O} B) \rightarrow \mathrm{O}(A \wedge B)$

(PDP): $\mathrm{O} A \rightarrow \mathrm{C} A$

$\mathrm{O}$ argumento pode ser apresentado como se segue:

1. $(\mathrm{O} A \wedge \mathrm{O} B) \wedge \neg \mathrm{C}(A \wedge B) \quad$ suposição (dilema moral).

2. $\mathrm{O} A \wedge \mathrm{O} B \quad$ de 1

3. $\neg \mathrm{C}(A \wedge B) \quad$ de 1

4. $(\mathrm{O} A \wedge \mathrm{O} B) \rightarrow \mathrm{O}(A \wedge B) \quad$ PA

5. $\mathrm{O}(A \wedge B) \quad$ de 2 e 4

6. $\mathrm{O}(A \wedge B) \rightarrow \mathrm{C}(A \wedge B) \quad$ PDP

7. $\mathrm{C}(A \wedge B) \quad$ de 5 e 6

8. $\neg \mathrm{C}(A \wedge B) \wedge \mathrm{C}(A \wedge B) \quad$ de 3 e 7 
Como 8 é uma contradição, temos de negar a suposição que permitiu derivála:

$$
\text { 15. } \neg((\mathrm{O} A \wedge \mathrm{O} B) \wedge \neg \mathrm{C}(A \wedge B)) \quad 1-8 \mathrm{I} \neg
$$

Filósofos como van Fraassen (1973) e Williams (1965) encontram nesse argumento uma razão para rejeitar PA, já que aceitam a existência de dilemas morais. Ora, como o problema discutido neste artigo é o de saber se há dilemas morais genuínos, não irei rejeitar PA simplesmente por pressupor que há dilemas morais.

Talvez o leitor esteja pensando há muito tempo no seguinte contraexemplo a PA. Considere o caso de Sofia. Ela tem a obrigação de salvar a vida da menina e a obrigação de salvar a vida do garoto, mas não tem a obrigação de salvar a vida dos dois ao mesmo tempo. Portanto, PA é falso.

Concordo com o exemplo acima. De fato, Sofia não tem a obrigação de realizar aquelas duas ações ao mesmo tempo. O problema é que esse exemplo não mostra que PA seja falso. A razão é simples: não há qualquer elemento temporal no princípio de aglomeração. O princípio apenas assere que se é obrigatório que $A$ e obrigatório que $B$, então é obrigatório que $A$ e $B$. O princípio não diz que $A$ e $B$ são ações obrigatórias ao mesmo tempo.

Há contraexemplos mais sérios a PDP; darei atenção especial a dois deles. $\mathrm{Na}$ verdade, acredito que há dois tipos principais de contraexemplos a PDP. O primeiro tipo, que aquele que irei apresentar, envolve a noção de promessa. Os contraexemplos de Sinnot-Armstrong (1984) estão justamente nesta direção, embora eu acredite que eles tenham sido corretamente respondidos (Ruffino, 1999). O segundo tipo envolve os contraexemplos do tipo Frankfurt (1969).

Suponha que um agente faça um empréstimo de dinheiro e prometa pagá-lo. No entanto, no momento em que ele deveria pagar a dívida, perde todo o dinheiro e é incapaz de pagá-la. Esse agente é incapaz de pagar a dívida, mas mesmo assim tem a obrigação de pagá-la. PDP portanto é falso. O agente tem a obrigação de pagar a dívida $(\mathrm{O} A)$, mas não é capaz de pagá-la $(\neg \mathrm{C} A)$.

Acredito que esse contraexemplo apresenta vários problemas. Em primeiro lugar, ele parece ser bem-sucedido porque não explicitamos seu elemento temporal. Intuitivamente, o agente tem a obrigação de pagar a dívida porque estamos pressupondo que ele é capaz de pagar a dívida em algum outro momento do tempo. 
Se esse agente, ao longo de toda a sua vida, for realmente incapaz de pagar a dívida, é implausível dizer que tem de realizar essa obrigação. Uma vez que contraiu a dívida, o agente tem a obrigação, na melhor das hipóteses, de se esforçar ao máximo para recuperar o dinheiro e pagá-la. Ou, para colocar em outros termos, se o agente era incapaz de pagar a dívida, não deveria ter feito aquela promessa. $\mathrm{O}$ agente seria condenável não por não pagar a dívida, mas por ter feito uma promessa que era incapaz de levar a cabo.

Mas suponha que o agente fosse capaz de pagar a dívida quando realizou a promessa e que, por algum motivo, ele perde todo o dinheiro. Por exemplo, no momento em que iria levar o dinheiro, um ladrão roubara tudo minutos antes. Pode-se dizer que ainda assim o agente tenha a obrigação de pagar a dívida, digamos, e que ele é incapaz de pagá-la. Mesmo que se defenda isso, o contraexemplo não é bemsucedido para falsear PDP. Para mostrar o porquê, é preciso recorrer ao conceito de capacidade máscara.

Michael Fara (2008) defendeu que a noção de máscara - muito comum com relação a disposições - pode ser aplicada a capacidades. Por exemplo, estamos propensos a acreditar que uma xícara de porcelana tem a propriedade disposicional de se quebrar. Mas podemos simplesmente mascarar a disposição da xícara de se quebrar ao revesti-la, digamos, com algum material protetor, um isopor, etc. Se fizermos isso, a xícara não perde a disposição de se quebrar, ocorre apenas que sua disposição foi mascarada. Não são apenas os objetos inanimados que têm propriedades disposicionais, mas também agentes. A disposição de um ladrão para roubar um carro pode ser mascarada pela presença da polícia. Fara argumenta que algumas capacidades dos agentes - assim como algumas de suas disposições - podem ser mascaradas. Por exemplo, um ladrão que não roubou um carro por causa da presença da polícia não deixa de ter a capacidade de roubar o carro, sua capacidade foi simplesmente mascarada. Neste artigo, pressuporei que a análise disposicional do conceito de capacidade de Fara está correta:

Análise disposicional: Um agente tem a capacidade para fazer $A$ nas circunstâncias $C$ se, e só se, ela tem a disposição para fazer $A$ quando, nas circunstâncias $C$, ela tenta fazer $A$. 
Presumindo que Fara esteja certo ao empregar a noção de máscara a capacidades, é fácil ver por que o exemplo do empréstimo não falsifica PDP. Sugeri que o agente tem a obrigação de dispender de todos os seus esforços para conseguir o dinheiro e pagar o empréstimo. Mas pode-se sustentar, contra o que sugeri, que o agente tem a obrigação de pagar o empréstimo. Mesmo que esse seja o caso, é falso que o agente não tem a capacidade de pagar o empréstimo. Ele tem a capacidade de pagar o empréstimo, pois tem a disposição de pagá-lo. Sua disposição de pagar o empréstimo foi mascarada pela falta de dinheiro, por isso sua capacidade também foi mascarada pela falta de dinheiro. Considere a análise do conceito de capacidade mascarada:

Uma capacidade de um agente para fazer $A$ nas circunstâncias $C$ é mascarada sse (2008, p.848)

(i) o agente tenta fazer $A$

(ii) as circunstâncias $C$ ocorrem

(iii) o agente retém a sua capacidade enquanto tenta fazer $A$; porém

(iv) o agente não é bem-sucedido em fazer $A$.

No exemplo, (i) o agente tenta pagar a dívida (ii) naquelas circunstâncias, retém (iii) sua capacidade enquanto tenta pagar a dívida, mas (vi) não é bem-sucedido em pagá-la. A capacidade do agente de pagar a dívida foi mascarada pelo fato de o ladrão ter roubado o dinheiro. Portanto, o contraexemplo não é bem-sucedido em falsear PDP precisamente porque o agente tem a capacidade (mascarada) de pagar a dívida.

É claro que você pode imaginar um caso em que o agente não estava disposto a pagar a dívida e, portanto, não tinha a capacidade. Neste caso, como eu disse anteriormente, o agente é condenável por ter feito uma promessa que não era capaz cumprir, precisamente porque não estava disposto a cumprir. Não é condenável por não fazer algo que é incapaz de fazer.

Vejamos outro contraexemplo a PDP. Um cientista insano resolve realizar um experimento e injeta uma droga num agente. $\mathrm{O}$ aspecto curioso é que a droga controla todas as suas ações, mas não as suas escolhas. Assim, o cientista controla o agente de tal modo a levá-lo a um prédio, portando um rifle, para matar determinada pessoa. $\mathrm{O}$ agente está determinado a pressionar o gatilho do rifle e a matar aquela pessoa, 
embora tenha a capacidade de escolher não o fazer. Mas o que ocorre é que o agente escolhe precisamente matar a pessoa. Nesse caso, o agente tem a obrigação de não matar aquela pessoa, mesmo que seja incapaz de não o fazer, pois as suas ações são determinadas pelo cientista. Assim, PDP é falso. O agente tem a obrigação de não matar a pessoa $(\mathrm{O} \neg A)$, mas não é capaz de não matá-la $(\neg \mathrm{C} \neg A)$.

O contraexemplo acima é um contraexemplo do tipo Frankfurt, ou seja, um contraexemplo que procura nos fazer abandonar o princípio de possibilidades alternativas: se um agente não pode agir diferente daquilo que agiu, então não é moralmente responsável pela ação que realizou. Em notação lógica, o princípio é o seguinte:

Princípio de possibilidades alternativas: $(A \wedge \neg \mathrm{C} A) \rightarrow \neg \mathrm{O} A$

Se o contraexemplo do tipo Frankfurt é um contraexemplo ao princípio acima, também o é ao princípio de que dever implica poder. Afinal, o contraexemplo terá de mostrar que $A \wedge \neg \mathrm{C} A$ (a afirmação do antecedente) e que, no entanto, OA (a negação do consequente). Como o princípio de que dever implica poder, por contraposição, é apenas $\neg \mathrm{C} A \rightarrow \neg \mathrm{O} A$, teríamos um contraexemplo a ele também.

Para responder ao contraexemplo, recorro novamente à análise de Fara do conceito de capacidade mascarada. De maneira bastante breve, a capacidade do agente de não pressionar o gatilho foi mascarada pela droga injetada pelo cientista. $O$ agente retém sua capacidade. E já que retém a capacidade, a antecedente da condicional é falsa. Portanto, o princípio é verdadeiro, já que a condicional do princípio é a material.

Há ainda um terceiro argumento que pode ser usado contra quem defende a existência de dilemas morais. Este não mostra que a suposição de dilemas morais permite, juntamente com princípios plausíveis, chegar a uma contradição (a respeito do argumento, ver van Fraassen 1973 e McConnell 1976). Mas a suposição dos dilemas leva a uma conclusão demasiado implausível: a de que, para qualquer ação, essa ação é obrigatória. Para mostrar isso, é preciso que recorramos novamente aos dois seguintes princípios:

(PA): $(\mathrm{O} A \wedge \mathrm{O} B) \rightarrow \mathrm{O}(A \wedge B)$ 
(PD): $\square(A \rightarrow B) \rightarrow(\mathrm{O} A \rightarrow \mathrm{O} B)$

E agora o argumento:

1. $(\mathrm{O} A \wedge \mathrm{O} B) \wedge \neg \mathrm{C}(B \wedge A)$

2. $\mathrm{O} A \wedge \mathrm{O} B$

3. $\neg \mathrm{C}(B \wedge A)$

4. $\square \neg(B \wedge A)$

5. $\square(B \rightarrow \neg \mathrm{A})$

6. $\square(B \rightarrow \neg \mathrm{A}) \rightarrow(\mathrm{O} B \rightarrow \mathrm{O} \neg A)$

7. $\mathrm{O} B \rightarrow \mathrm{O} \neg A$

8. $\mathrm{O} B$

9. $\mathrm{O} \neg A$

10. $\mathrm{O} A$

11. $\mathrm{O} \neg A \wedge \mathrm{O} A$

12. $(\mathrm{O} \neg A \wedge \mathrm{O} A) \rightarrow \mathrm{O}(\neg A \wedge A)$

13. $\mathrm{O}(\neg A \wedge A)$

14. $\square((\neg A \wedge A) \rightarrow B) \rightarrow(\mathrm{O}(\neg A \wedge A) \rightarrow \mathrm{O} B)$

15. $\square((\neg A \wedge A) \rightarrow B)$

16. $\mathrm{O}(\neg A \wedge A) \rightarrow \mathrm{O} B$ suposição (dilema moral).

de 1

de 1

de 3

de 4

PD

de 5 e 6

de 2

de 7 e 8

de 2

de 9 e 10

PA

de 11 e 12

PD

verdade lógica

de 14 e 15

Agora, através de um simples modus ponens a partir de 13 e 16, temos o seguinte:

\section{7. $\mathrm{O} B$, para qualquer $B$}

Como 17 certamente viola o senso comum, temos de negar a suposição que permitiu derivá-la, que é a conclusão de que não há dilemas morais:

18. $\neg((\mathrm{O} A \wedge \mathrm{O} B) \wedge \neg \mathrm{C}(B \wedge A))^{3}$

Uma saída para o defensor do conflito ontológico de obrigações é adotar uma lógica paraconsistente, em que o princípio de explosão (a saber, 15) não é uma verdade lógica. Ele poderá assim aceitar simultaneamente dilemas morais e os 
princípios supracitados. O problema é precisamente rejeitar o princípio de explosão. Não vejo boas razões para rejeitá-lo; argumentar que ele é plausível porque há dilemas morais não é uma boa estratégia pelo mesmo motivo que vimos anteriormente com relação ao princípio de aglomeração. Claro que alguém pode defender que o princípio de explosão é implausível dando argumentos independentes. Mas essa discussão foge do escopo deste ensaio.

Se ao menos um dos três argumentos apresentados é cogente, então não há dilemas morais. Acredito que os argumentos sejam cogentes, mas reconheço que ainda permanece a intuição de que há casos genuínos de conflitos de obrigações. A seção final deste artigo é uma tentativa de mostrar que essa intuição é uma ilusão.

\section{Um conflito epistêmico}

A primeira parte deste artigo foi negativa. Defendi que o argumento fenomenológico não é cogente, e que também a distinção entre deveres prima facie e simpliciter não é bem-sucedida para solucionar o problema. Nesta parte procuro mostrar como o argumento fenomenológico pode ser reconstruído, e também procuro mostrar por que a intuição de que há dilemas morais não nos justifica racionalmente a aceitar que há dilemas morais.

Esta resposta repousa na distinção que expus no início do artigo entre os conflitos epistêmicos e ontológicos de obrigações. Os conflitos epistêmicos envolvem duas ou mais supostas obrigações em que o agente não sabe o que fazer. Os conflitos ontológicos envolvem dois cursos de ação obrigatórios em que o agente é incapaz de realizá-los. Dilemas morais genuíno são conflitos desse último tipo. Até aqui, discuti o problema de saber se há um conflito ontológico de obrigações. Vimos que a sua suposição, com mais alguns princípios plausíveis, leva-nos a um absurdo, de modo que seria mais razoável negar a existência de um conflito ontológico do que esses princípios plausíveis. O que resta, entretanto, é explicar a intuição de que há conflitos genuínos de obrigações.

Considere todos os casos de conflitos de obrigações mencionados neste artigo. Todos eles são muito intuitivos e podem perfeitamente ocorrer. Uma proposta plausível é a de que esses casos são conflitos epistêmicos. O agente, diante daquela situação, não sabe o que fazer (em virtude de sua limitação cognitiva). Não é preciso supor adicionalmente que há um conflito ontológico de obrigações. $\mathrm{O}$ agente tem 
razões para acreditar que as duas ações são obrigatórias, e que ele não pode realizá-las conjuntamente. Mas disso não se segue que ele esteja diante de duas ações obrigatórias, e que seja impossível realizá-las.

Anteriormente, o argumento fenomenológico foi apresentado a favor da tese de que há um conflito ontológico de obrigações. A objeção anteriormente apresentada ao argumento foi a de que a melhor explicação para o arrependimento apropriado de $S$ não é a existência de dilemas morais, mas a crença de $S$ que está diante de um dilema moral. Esse argumento pode ser agora devidamente reformulado.

1. Se $S$ está numa situação em que não sabe o que fazer diante de dois supostos cursos de obrigações, então arrepende-se apropriadamente.

2. $S$ arrepende-se apropriadamente.

3. Logo, $S$ está numa situação em que não sabe o que fazer diante de dois supostos cursos de obrigações.

$\mathrm{O}$ argumento fenomenológico pode ser usado a favor do conflito epistêmico de obrigações. A melhor explicação para o arrependimento apropriado de $S$ é a suposição de que $S$ está diante de um conflito epistêmico de obrigações.

$\mathrm{O}$ argumento fenomenológico era um importante argumento a favor dos conflitos ontológicos de obrigações. Penso que, numa formulação adequada, o argumento fenomenológico nos compele a aceitar o conflito epistêmico de obrigações, nada mais. Esta conclusão não é implausível. Pelo contrário, é trivial que muitos agentes estão em situações em que acreditam (mesmo justificadamente) estar diante de dois cursos obrigatórios de ação e que são incapazes de realizá-los conjuntamente.

Para explicar o aspecto intuitivo dos casos que apresentei neste artigo, não é preciso supor que há conflitos ontológicos de obrigações. Casos como aqueles podem ocorrer. Mas não são situações em que se exige que o agente faça o impossível. São situações tão difíceis que o agente acredita que está diante de um dilema moral. $\mathrm{O}$ agente crê que tem de realizar duas ações obrigatórias e que é incapaz de realizar essas duas ações conjuntamente. Como somos agentes falíveis, é natural que não saibamos o que fazer em diversas situações. Rejeitar a existência de conflitos ontológicos de obrigações não é violar o senso comum. O que o senso comum nos compele a aceitar são conflitos epistêmicos de obrigações. 
Além disso, se o conflito que há é epistêmico, não temos de recusar aqueles princípios plausíveis usados nos três argumentos da seção anterior. Os defensores dos conflitos ontológicos de obrigações têm a dificuldade adicional de lidar com os argumentos que apresentei na seção anterior. Isso é curioso, pois o defensor dos conflitos ontológicos deveria justamente preservar o senso comum, uma vez que se apoia na intuição de senso comum de que há dilemas morais. Mas a aceitação de um conflito ontológico viola princípios realmente intuitivos. O que defendi permite acomodar tanto o aspecto intuitivo de que há dilemas morais (que são os conflitos epistêmicos), como aqueles princípios plausíveis. Além disso, essa tese é ontologicamente mais econômica, pois não supõe a existência de um conflito genuíno de obrigações.

Finalmente, a distinção entre os conflitos epistêmicos e ontológicos talvez solucione casos simétricos de obrigações. Como vimos anteriormente, há casos nos quais, presumivelmente, temos obrigações moralmente simétricas. Por exemplo, um agente pode ter a obrigação de salvar um bebê $A$ e ter a obrigação de salvar um bebê $B$, e ambos os indivíduos são gêmeos idênticos. Nesse caso, parece que nenhuma das obrigações revoga a outra. $\mathrm{O}$ que se pode defender é que, rigorosamente falando, as obrigações não são moralmente simétricas. Ocorre apenas que não sabemos qual ação revoga a outra. Um consequencialista, por exemplo, poderia defender que temos a obrigação de salvar o indivíduo que promover as melhores consequências ao longo da vida. O problema é que não sabemos qual desses indivíduos promoverá as melhores consequências. Mas este é um problema epistêmico, e daí não se segue que tenhamos obrigações moralmente simétricas. Obviamente não tenho a pretensão de desenvolver uma resposta bem-sucedida para esses supostos casos de obrigações simétricas, mas é plausível pensar que há casos em que estamos justificados acreditar que são moralmente simétricos, mas não são de fato simétricos.

\section{Conclusão}

Dois aspectos aqui discutidos merecem uma atenção adicional. Primeiro, o argumento fenomenológico pode ser adequadamente formulado como uma inferência a favor da melhor explicação. Segundo, o conceito de capacidade mascarada pode jogar luz nas discussões sobre o princípio de que dever implica poder. Finalmente, procurei neste ensaio tornar plausível a tese de que não há um conflito ontológico de 
obrigações. Uma argumentação cogente a favor do conflito ontológico de obrigações deverá levar em conta os aspectos aqui brevemente discutidos. 
Notas:

${ }^{1}$ Este artigo é o resultado de parte de uma pesquisa de iniciação científica realizada na Universidade Federal de Ouro Preto. Ao longo dos anos, tive a oportunidade de apresentar as ideias deste artigo em algumas comunicações. Desidério Murcho e Luiz Helvécio Marques Segundo me ajudaram com várias objeções. Rafael d'Aversa me fez atentar a um ponto extremamente importante, que irei trabalhar em outro artigo. Lucas Miotto corrigiu uma versão inicial deste artigo e deu ótimas contribuições. Agradeço aos pareceristas desta revista que me ajudaram a corrigir as falhas deste artigo.

2 Doutorando em Filosofia pela Durham University, Durham, Inglaterra.

${ }^{3}$ Note que este argumento é um caso de inconsistência também. Por exemplo, em 14, poderíamos introduzir a premissa ' $\square((\neg A \wedge A) \rightarrow \neg \mathrm{B}) \rightarrow(\mathrm{O}(\neg A \wedge A) \rightarrow \mathrm{O} \neg \mathrm{B})$. Como temos "OB" na premissa 8, utilizando $\mathrm{PC}$ podemos derivar “ $\neg \mathrm{O} \neg \mathrm{B}$ ”. E aí teríamos uma contradição: $\mathrm{OB} \wedge \neg \mathrm{O} \neg \mathrm{B}$. Agradeço a um parecerista deste periódico por notar este ponto. 


\section{Referências Bibliográficas}

Fara, Michael (2008), 'Masked Abilities and Compatibilism', Mind, 117 (468): pp. 843-865.

Frankfurt, Harry (1969). 'Alternate Possibilities and Moral Responsibility,' Journal of Philosophy 66, pp. 829-39.

Greene, J.D. (2009). 'The cognitive neuroscience of moral judgment', in The Cognitive Neurosciences IV, M.S. Gazzaniga, Ed. MIT Press, Cambridge, MA.

Lemmon, E.J. (1962). “Moral Dilemmas,” The Philosophical Review, 70: 139-158.

Lemmon, E. J. (1965). 'Deontic Logic and the Logic of Imperatives,' Logique et Analyse, 8: pp. 39-71.

Marcus, Ruth Barcan (1980). 'Moral Dilemmas and Consistency,' The Journal of Philosophy, 77: pp. 121-136.

McConell, T. (2010). 'Moral Dilemmas', in Stanford Encyclopedia of Philosophy, E. Zatta editor.

Ross, W.D. (1930). The Right and the Good, Oxford: Oxford University Press.

Ruffino, M. (1999). 'Promessas Impossíveis, Situações de Conflito Moral e O Princípio Deve Implica Pode. Manuscrito, v.22, n.2, p.345-366.

Sinnot-Armstrong, W. (1984). 'Ought Conversationally Implies Can,' The Philosophical Review XCIII, pp. 249-61.

Van Fraassen, Bas C. (1973). 'Values and Heart's Command'. The Journal of Philosophy, Vol. 70, No. 1 (Jan. 11) pp. 5-19.

Williams, Bernard. (1965). "Ethical Consistency," Proceedings of the Aristotelian Society (Supplement), 39: 103-124. 